\title{
In the era of total mesorectal excision: adjuvant radiotherapy may be unnecessary for pT3NO rectal cancer
}

\author{
Jun-xin Wü, Yu Wang, Na Chen, Lu-chuan Chen, Peng-gang Bai and Jian-ji Pan*
}

\begin{abstract}
Background: Due to the Total Mesorectal Excision (TME) surgery made a good local control,the role of radiotherapy in the treatment of PT3NO rectal cancer is debated and whether this group of patiens were overtreated has been a controversy recently. This study aimed to evaluate the value of adjuvant radiation after TME and survival outcome for patients with pT3NO rectal adenocarcinoma.
\end{abstract}

Methods: From January 2003 to December 2011, a total of 141 patients with pT3NO rectal cancer after radical resection with the principle of Total Mesorectal Excision (TME) were enrolled. Among them, 42 patients (29.8\%) got adjuvant chemotherapy (CT) and the remaining cohort received chemoradiotherapy (CRT). The 5-year overall survival rate (OS), 5-year disease free survival rate (DFS), 5-year local recurrence free survival rate (LRFS), 5-year local recurrence rate (LRR) and the prognostic factor of this cohort were analyzed.

Results: The median follow-up interval time was 44 months. The 5-year OS and DFS rates were $82.4 \%$ and $71.9 \%$ for the whole group. There were no significant differences in 5 -year OS ( $83.3 \%$ vs $72.4 \%, P=0.931)$ or LRFS rates (81.7\% vs $74.5 \%, P=0.157)$ for patients between CT group and CRT group. Multivariate cox regression analysis suggests that preoperative serum CEA level, number of lymph nodes inspected, perirectal fat infiltration were independent prognostic factors for 5-year DFS. The recurrence rate was not affected by radiotherapy for patients with lower and midrectal cancer.

Conclusions: For the patients with pT3N0 rectal cancer, addition radiation after TME surgery made no significant differences in survival rate and local recurrence rate. The effect of adjuvant radiotherapy needs further evaluation.

Keywords: Rectal cancer, Post-operative radiotherapy, Prognosis factors

\section{Introduction}

Rectal cancer is still a common tumor among the world, while the major treatment for patients with a rectal malignancy is radical surgical excision. For patients with resectable rectal cancer, an optimal surgery could get a satisfactory local control; while for those with advanced tumors, a curative resection may be especially difficult because of the special location of pelvis and always with high local failure rates [1]. As a result, a multidisciplinary synthetic therapy is of great important value. In the 1990s, several researches have suggested that postoperative

\footnotetext{
*Correspondence: junxinwu@126.com; panjianji@126.com Department of Radiation Oncology, Fujian Provincial Cancer Hospital, Provincial Clinical College of Fujian Medical University, Fuzhou, Fujian P R China
} PR China

chemoradiotherapy can cut down local recurrence rates $[2,3]$. So the US National Institutes for Health advocated that the postoperative chemoradiotherapy as standard regimen for patients with stage II or III rectal cancer [4]. Of note, all these previous researches were conducted in the times of conventional surgery method. More over, among the patients involved in previous studies, the respective proportion of patients with stage II and III remained unknown and the separate survival outcome of stage II rectal cancer were not illuminated too. Nowadays, radical radical surgery with the principle of TME (low anterior resection LAR or abdominalperineal resection APR) could lower the local recurrence rate significantly $[5,6]$. The TME has showed superior results than conventional surgery and has been the standard operation form for a 
resectable rectal cancer. With the low recurrence rate in the new times, the effect of conventional trimodality therapy (surgery plus chemotherapy plus radiotherapy) for stage II and III rectal cancer seems to be reconsidered. Consequently, the real benefit of addition radiotherapy after surgery was a question need to be investigated [7].

As mentioned above, for the pT3N0 rectal patients, several retrospective studies showed the low rates of local recurrence ranging from $4.1 \%$ to $6.5 \%$ after TME surgery alone $[5,6]$. What's more, many studies have showed the addition of radiation therapy did not improve the survival outcome and local recurrence rate [7-9]. This result in favor of the point of view that for pT3N0 rectal cancer, routine adjuvant radiation therapy after TME may be unnecessary and overtreatment. Many researchers argue that the pT3N0 rectal cancer may have an "intermediate" risk of recurrence, and suggest that the radiation therapy need further investigated $[10,11]$. To evaluate the effect of adjuvant radiotherapy in patients with T3N0 rectal cancer after TME, we studied the influence of adjuvant radiotherapy on the survival and the recurrence rate among this cohort of patients.

\section{Materials and methods}

\section{Patient selection}

Patients with resectable adenocarcinoma and treated with TME at Fujian Provincial Cancer Hospital between January 2003 and December 2011 were collected. The patient selection criteria come as follows: (1) between 20-80 years old; (2) without neo-adjuvant chemotherapy and radiotherapy; (3) received radical resection with the principle of TME; (4) biopsy-proven pT3N0 rectal cancer according to the $7^{\text {th }}$ version of AJCC guideline; (5) no evidence of distant metastases and serious comorbidity before surgery; (6) received adjuvant chemotherapy (CT) after surgery. Ultimately, 141 patients were included in this study. Patients were split into CRT and CT group and evaluated for age, sex, preoperative serum carcinoembryonic antigen (CEA) level, histologic differentiation, cell histology, grade of differentiation, total number of lymph nodes retrieved, lymphovascular invasion, adjuvant radiotherapy, development of recurrence or metastasis and survival. Before surgery, patients received a complete physical examination, blood routine test, liver and renal function test, proctoscopy, pelvic CT or MRI, chest X-ray and the level of CEA. Those who had a poor physical condition or metastasis were excluded from our study.

\section{Treatment}

Surgery method: except the upper rectal cancer $(10 \mathrm{~cm}$ above the anal verge), all patients got surgery with the principle of TME. The operation method was selected according to the digital rectal and proctoscopy examination. LAR was performed in 97 patients; the remaining 44 patients underwent APR. The surgery were operated by at least two of experienced surgeons. The hypogastric nerve, pelvic autonomic nerve plexus and arteria rectalis media were protected as far as possible, lymph drainage area and fat tissue were removed. The distal mesorectal margin was at least $2 \mathrm{~cm}$ away from the tumor, for those with a distance ranging from 1 to $2 \mathrm{~cm}$ from the anal verge; an intraoperative frozen pathological examination should be conducted to confirm the negative surgical margins.

Chemotherapy program: All of the patients received adjuvant chemotherapy or concurrent chemoradiotherapy. The 5-Fluorouracil (5-FU) -based chemotherapy program consisted of $2250 \mathrm{mg} / \mathrm{m} 2$ of 5-FU civ for 46 hours and $400 \mathrm{mg} / \mathrm{m} 2$ of CF for $\mathrm{d} 1$, and Oxaliplatin for $\mathrm{d} 1$ every 14 days for 8-12 cycles. In case of patients treated by oralling Xeloda, the patients took orally $1250 \mathrm{mg} / \mathrm{m} 2$ twice daily days 1-14 every 3 weeks to a total of 6 months. Concurrent chemotherapy: $225 \mathrm{mg} / \mathrm{m} 2$ of 5 -Fu over 24 hours 5 days/week during radiotherapy or took Xeloda $825 \mathrm{mg} / \mathrm{m} 2$ twice daily 5 days per week during radiotherapy.

Radiation therapy: for the CRT group, the patients began additional radiation therapy within 4 weeks after TME. Of these patients, 27 got conventional radiotherapy,11 received three dimensional conformal radiation therapy, the remaining 4 received Intensity Modulated Radiation Therapy. A $6 \mathrm{MV}$ dual photon linear accelerator was used to deliver the X-ray and three or five-field box technique was applied to the treatment planning. The radiation field was as follows: the upper bound was the level of L5-S1, the lower bound was the obturator formamen (Dixon) or $1.5 \mathrm{~cm}$ inferior of the metal sign (Mile's), the lateral bound was $2.0 \mathrm{~cm}$ lateral to the widest bony margin of the true pelvis. A total dose of 50 Gy was delivered in 25 fractions of 2 Gy per day.

\section{Definition of treatment failure}

Through reading the follow up data of the 141 patients, the treatment failures were found out. Local-failure was defined as any recurrence occured within the pelvis, including the tumor bed, regional lymph nodes, anastomosis, or perineal scar. While recurrence detected in the liver, lung, brain, and other organs or lymph nodes outside the pelvis were regarded as distant failure.

\section{Follow up}

Patients were followed up routinely at 3-month intervals for the first 2 years, at 6-month intervals for the next 5 year, and once a year thereafter. The follow up examination consisted of a physical examination, measuring of CEA, chest X-rays, the whole body ECT, abdominal and pelvic CT or MRI. Survival time was calculated from the date of surgery to the date of die or loss to follow-up; local-recurrence free survival LRFS was from the date of 
surgery to the date of having local relapse; disease-free survival DFS was time from the date of surgery to the date of local recur, metastasis or die of the rectal cancer.

\section{Statistical analysis}

SPSS 17.0 was used to analysis the data. 5-year OS, DFS and LRFS curves were calculated according to the Kaplan-Meier method and log rank test was used to distinguish the differences between groups. Chi-square tests was used to paired the clinicopathologic characteristics of two groups. The Cox regression was used for examining the independent factors associated with survival outcome. $\mathrm{P}<0.05$ was considered statistically significant.

\section{Results}

\section{Clinicopathologic characteristics}

Of the 141 patients, 42 received CRT, 99 accepted CT. All of the patients had a Karnofsky score higher than 90 point. Radiotherapy was performed significantly more commonly in those with lower rectal cancer $(\mathrm{P}=.003)$ and those with less number of lymph nodes $(\mathrm{P}=.001)$. The mean number of the lymph nodes was 16.15 (range, $0-50$ ). In addition to above,the two groups were well matched in other clinicopathologic items such as age, sex, pre-operative level of CEA, histological type, grade of differentiation, maximum diameter of tumor, lymph-vascular invasion, perirectal fat infiltration (Table 1).

\section{Follow up and recurrence}

The median follow up time was 44 months (range, 3-104 months). The proportion of patients followed up more than 60 and 36 months were $63.8 \%$ and $22 \%$. During the follow up, a total of 23 patients (16.3\%) relapsed. The 5 year cumulative recurrence rate was $8.2 \%$. There was no significant difference in 5 year local recurrence rate between CT and CRT group (5.3\% vs $14.3 \%, \mathrm{P}=0.140)$. Of the 23 recured patients, 11 patients suffered from local recurrence $(7.8 \%), 17$ patients had distant metastasis (12.1\%), both local and distant failures happened to 5 patients (3.5\%). Liver was the most common site of metastasis (39.1\%), then was the lung (30.4\%). Until the last follow up time, up to 20 patients died of rectal cancer, 1 patient died of other reasons. The median local recurrence and distant failure time were 44 months (range, 3-104 months) and 40 months (range, 3-104 months); The median survival time after local recurrence and distant metastasis were 17 months (0-49 months) and 21 months (0-49 months).

\section{Survival}

The overall 5-year OS and DFS rates were $82.4 \%$ and $71.9 \%$ for the whole group (Figure 1, Figure 2). For the CT and CRT groups, the 5-year OS rates were $83.3 \%$ versus $72.4 \%(\mathrm{P}=0.931)$, respectively (Figure 3$)$, and the 5 -year LRFS rates were $81.7 \%$ versus $74.5 \%(P=0.157)$
Table 1 Clinicopathologic characteristics of patients

\begin{tabular}{|c|c|c|c|}
\hline Characteristics & $\begin{array}{l}\mathrm{CT} \\
\mathrm{n}=99(\%)\end{array}$ & $\begin{array}{l}\text { CRT } \\
n=42(\%)\end{array}$ & $P$ value \\
\hline Age, years & 56 & 56.5 & 0.814 \\
\hline$<50$ & $31(31)$ & $14(33)$ & \\
\hline$\geq 50$ & $68(69)$ & $28(67)$ & \\
\hline Sex & & & 0.966 \\
\hline Male & $68(69)$ & $29(69)$ & \\
\hline Female & $31(31)$ & $31(31)$ & \\
\hline Median Karnofsky scores & 90 & 90 & \\
\hline Preoperative CEA (n g/m L) & & & 0.088 \\
\hline$<5$ & $66(67)$ & $34(81)$ & \\
\hline$\geq 5$ & $33(33)$ & $8(19)$ & \\
\hline Distance to anal $(\mathrm{cm})$ & & & 0.003 \\
\hline $0-5$ & $34(34)$ & $27(64)$ & \\
\hline $6-10$ & $44(44)$ & $12(29)$ & \\
\hline $11-15$ & $21(21)$ & $3(7)$ & \\
\hline Surgical type & & & 0.000 \\
\hline$<$ Dixon & $79(80)$ & $18(43)$ & \\
\hline Miles & $20(20)$ & $24(57)$ & \\
\hline Histologic type & & & 1.000 \\
\hline Adenocarcinoma & $94(95)$ & $40(95)$ & \\
\hline Mucinous adenocarcinoma & $5(5)$ & $2(5)$ & \\
\hline Grade of differentiated & & & 0.665 \\
\hline Well & $15(15)$ & $9(21)$ & \\
\hline Moderately & $81(82)$ & $32(76)$ & \\
\hline Poor & $3(3)$ & $1(3)$ & \\
\hline Maximum diameter $(\mathrm{cm})$ & & & 0.900 \\
\hline$<5$ & $53(54)$ & $22(52)$ & \\
\hline$\geq 5$ & $46(46)$ & $20(48)$ & \\
\hline Number of retrieved lymph nodes & $37(37)$ & & 0.001 \\
\hline$<15$ & $62(63)$ & $29(69)$ & \\
\hline$\geq 15$ & & $13(31)$ & \\
\hline Lymph-vascular invasion & & & 0.084 \\
\hline Yes & $3(3)$ & $6(14)$ & \\
\hline No & $96(97)$ & $36(86)$ & \\
\hline Perirectal fat infiltration & & & 0.323 \\
\hline Yes & $36(36)$ & $18(43)$ & \\
\hline No & $63(64)$ & $24(57)$ & \\
\hline
\end{tabular}

(Figure 4). The 5 -year DFS rate was significantly better in patients with $\leq 15$ than in those with $>15$ examined lymph nodes $(\mathrm{P}=0.001$, Figure 5$)$.

\section{Univariate analysis and cox regression}

In the univariate analysis, preoperative level of CEA, the number of lymph nodes retrieved $(<15$ and $\geq 15)$, the differentiation of the tumor and the perirectal fat infiltration 


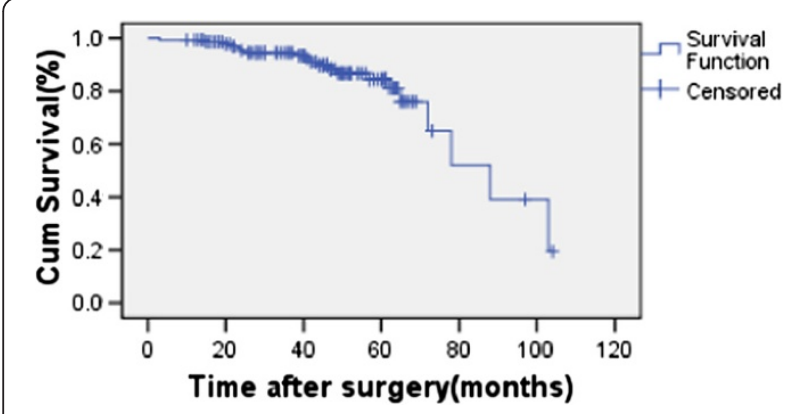

Figure 1 Overall survival of all patients.

were significant prognostic factors affecting disease-free survival rate (Table 2). In the multivariate analysis, preoperative level of CEA, number of lymph nodes and the perirectal fat infiltration were independent factors associated with significantly worse DFS (Table 3).

\section{Effect of radiotherapy on recurrence}

Patients with mid to lower rectal cancer had a higher local recurrence rate than those with upper rectal cancer, while the difference was not significant $(P=0.115)$. No matter of the height of rectal cancer, radiation did not make significant improvement in local recurrence rate (Table 4). Similarly, local recurrence rate was also higher in patients with $\leq 15$ (13.6\%) than in those with $>15$ (2.7\%) examined lymph nodes $(\mathrm{P}=.015)$. According to different number of lymph nodes, the recurrence rate differed not significantly between the CT and CRT groups (Table 5).

\section{Discussion}

Many studies showed the post-operative radiation could decrease the rate of local relapse and improve survival rate for stage II and III rectal cancer. While, with the introduction and application of TME in rectal cancer which significantly reduced the recurrence rate of resectable rectal cancer, the routine postoperative radiation may not be necessary, especially for subgroup patients of pT3N0 rectal cancer, with an "intermediate" risk for recurrence. Oppositely, the new role of preoperative RT has been confirmed for stage II or III rectal cancers. The

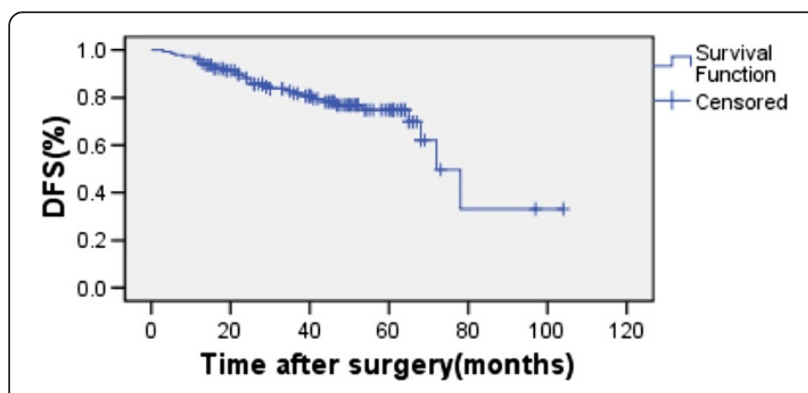

Figure 2 Disease-free survival of all patients.

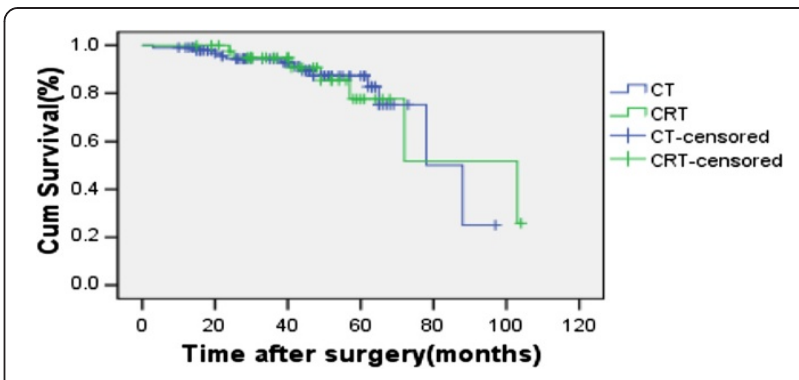

Figure 3 Overall survival rates with or without radiotherapy.

MRC CR07/NCIC-CTGC016 conducted a multicenter randomized trial comparing preoperative radiotherapy with selective postoperative chemoradiotherapy. The median follow-up time was 4 years and it came to a result that preoperative radiotherapy significantly improved the 5-year DFS and reduced local recurrence rate [12]. To evaluate the value of pre-operative radiation for patients with resectable rectal cancer who undergone TME, a prospective randomized trial contained of 1861 was conducted. By comparing the outcome between the TME group and pre-operative $5 * 5$ Gy short-term radiation plus TME group, the study showed that preoperative radiotherapy could significantly reduce the local recurrence rate. The rate was $5.6 \%$ in pre-operative radiation group while the TME group was $10.9 \%$ (P < 0.001) [13]. In the study of Kapiteijn [14], the local recurrence rate at two years was $2.4 \%$ in the pre-operative radiation plus TME group and 8.2 percent in the TME group $(\mathrm{P}<0.001)$, confirming that for patients received TME, short-term preoperative radiotherapy reduces the risk of local recurrence. As a result, many researchers suggest pre-operative radiation has more advantage over post-operative radiation. Because of the low local recurrence rate after an optimal TME surgery, the risk of additional radiation in patients with T3N0 rectal cancer may outweigh the potential advantages. Nissan et al. [6] reported patients with pT3N0 rectal cancer had a $4.1 \%$ local recurrence rate and $71.4 \%$ overall survival with TME alone,and the local and distant RFS and DSS were similar with pT2N0 rectal cancer. According to the report of Merchant NB [15], the overall local recurrence was $9 \%$ and overall survival was $75 \%$ for patients with T3N0 rectal cancer who underwent surgery without adjuvant treatment. Also, many researches showed additional postoperative radiotherapy did not alter local recurrence or survival after TME in patients with stage IIA rectal cancer [8,9]. They proposed addition postoperative radiation may be overtreatment for patients with stage II A rectal cancer if they had no other risk factors. A study conducted by Gunderson showed that patients with T3N0 rectal cancer had similar prognosis with T1/ 2 N1 rectal cancer,and the 5-year OS and DFS were $84 \%$ 


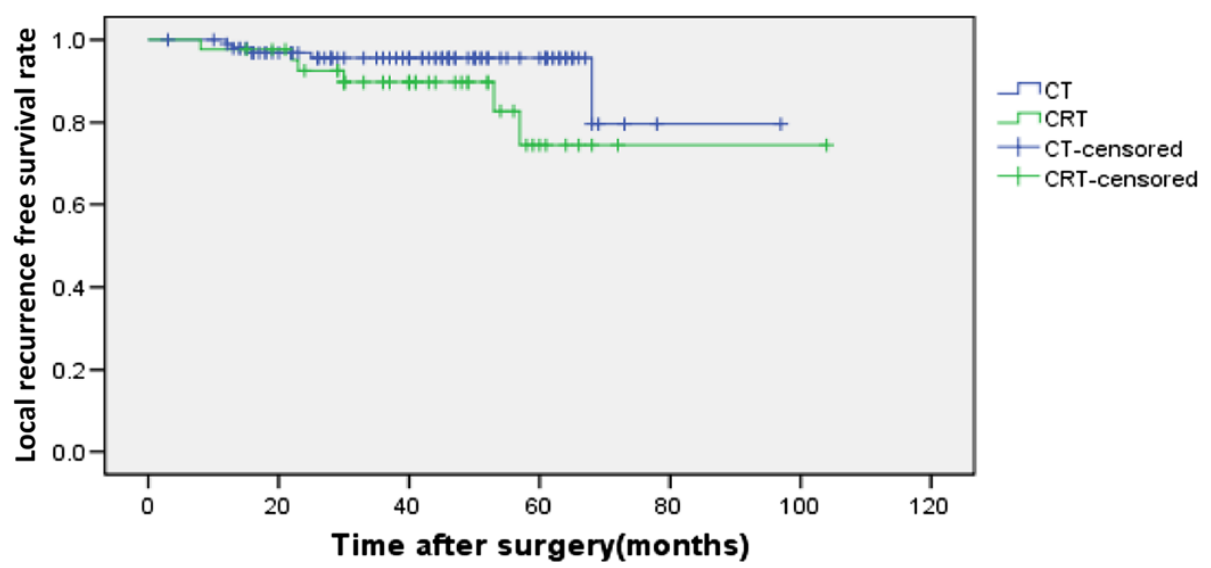

Figure 4 Local-recurrence free survival rates with or without radiotherapy $(\mathrm{N}=141)$. The difference of the overall survival between the two groups was not significant ( $P=0.157)$. CT chemotherapy, $C R T$ chemoradiotherapy.

and $69 \%$ after surgery plus chemotherapy for this subgroup, and adding radiotherapy did not improve the survival, suggesting that a trimodality treatment approach was unnecessary [16]. Moreover, the morbidities and poor functional outcomes induced by radiotherapy always affect the life quality of patients. Ooi reported that for rectal patients receiving postoperative radiotherapy, the acute toxicities incidence rate is ranging from $4 \%$ $48 \%$ and $3 \%-10 \%$ of cases need hospitalization care [17]. In the long-term, radiation associated morbidities and dysfunctional outcomes such as fibrosis, autonomic nerve injury, bladder and sexual dysfunction were more common in patients receiving pelvic radiation compared to those without radiation [18-21]. Thus, for the patients with pT3N0 rectal cancer, the role of radiotherapy needs to be carefully evaluated.

In our retrospective analysis of 141 patients with T3N0 rectal cancer,we found that the 5-year OS and LRFS were not significantly different between CT and CRT group (Figure 3, Figure 4). The 5-year OS, DFS and local recurrence rate of the whole group were $82.4 \%$, $71.9 \%$ and $7.8 \%$, respectively; similar with the previous reports $[7-9,16,22,23]$. In terms of the effect of radiation on local recurrence rate,we found that no matter the number of lymph nodes, there was no significant difference between the CT and CRT groups. For the different height of the rectal cancer, radiation did not affect the recurrence rate of them either.

The risk factors that associated with the local recurrence have been inconsistently reported in many studies. In the study made by Nissan et al. [6], univariate analysis showed the presence of LVI, abnormal preoperative CEA, and older age were associated with pelvic recurrence, while the multivariate analysis showed only abnormal preoperative CEA was independent factors for DFS (RR $=3.1$; 95\% confidence interval $[C I], 1.2-8.1$; $\mathrm{P}=0.01)$ and $\operatorname{DSS}(\mathrm{RR}=2.9,95 \% \mathrm{CI}: 1.1-7.6, \mathrm{P}=0.02)$. The involvement of the circumferential resection margin and age $>60$ years were also reported associated with adverse oncologic outcomes [9]. Merchant et al.showed the

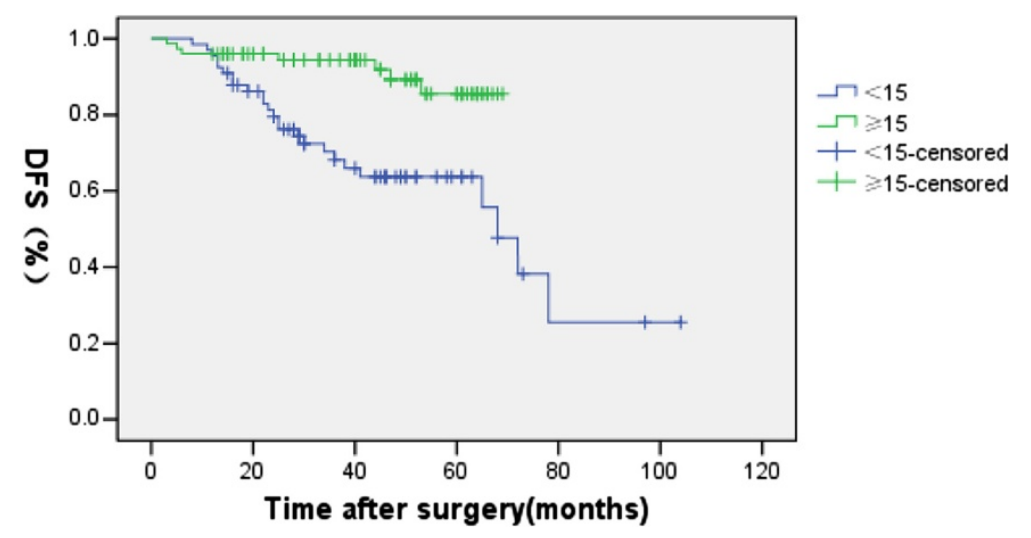

Figure 5 Disease-free survival rates with $<15$ and those $\geq 15$ lymph nodes retrieved $(P=0.001)$. 
Table 2 The log-rank univariate analysis of patients

\begin{tabular}{|c|c|c|c|c|c|}
\hline Factors & Number & 3-year DFS (\%) & 5-year DFS (\%) & $x^{2}$ & $P$ value \\
\hline Age (year) & & & & 2.104 & 0.14 \\
\hline$<50$ & 45 & 85.4 & 76.9 & & \\
\hline$\geq 50$ & 96 & 78.8 & 55.4 & & \\
\hline Sex & & & & 1.208 & 0.272 \\
\hline Male & 97 & 80.3 & 68.5 & & \\
\hline Female & 44 & 83.7 & 69.7 & 6.563 & 0.010 \\
\hline \multicolumn{6}{|l|}{ Pre-operative CEA (n g/m L) } \\
\hline$<5$ & 100 & 87.4 & 74.1 & & \\
\hline$\geq 5$ & 41 & 65.1 & 52.7 & & \\
\hline Distance to anal $(\mathrm{cm})$ & & & & 3.299 & 0.19 \\
\hline $0-5$ & 61 & 80.3 & 68.0 & & \\
\hline $6-10$ & 56 & 79.9 & 61.8 & & \\
\hline $10-15$ & 24 & & & & \\
\hline Operation type & & & & 1.958 & 0.162 \\
\hline Dixon & 97 & 85.8 & 74.1 & & \\
\hline Miles & 44 & 71.5 & 58.1 & & \\
\hline Histologic type & & & & 3.053 & 0.081 \\
\hline Adenocarcinoma & 134 & 83.1 & & & \\
\hline Mucinous adenocarcinoma & 7 & 44.8 & & & \\
\hline Grade of differentiated & & & & 29.906 & 0.000 \\
\hline Well & 24 & 80.8 & 68 & & \\
\hline Moderately & 113 & 83.5 & 68 & & \\
\hline Poor & 4 & 4.7 & & & \\
\hline Maximum diameter $(\mathrm{cm})$ & & & & 0.106 & 0.74 \\
\hline$<5$ & 75 & 80.5 & 59.5 & & \\
\hline$\geq 5$ & 66 & 81.9 & 70.6 & & \\
\hline Number of retrieved lymph nodes & & & & 11.616 & 0.000 \\
\hline$<5$ & 66 & 68.2 & 57.4 & & \\
\hline$\geq 5$ & 75 & 93 & & & \\
\hline Lymph-vascular invasion & & & & 0.087 & 0.768 \\
\hline Yes & 9 & 85.7 & 22.4 & & \\
\hline No & 132 & 81.6 & 71.9 & & \\
\hline Radiation & & & & 2.787 & 0.095 \\
\hline Yes & 42 & 87.9 & 74.5 & & \\
\hline No & 97 & 91.2 & 90.7 & & \\
\hline Perirectal fat infiltration & & & & 3.953 & 0.009 \\
\hline Yes & 55 & 76.2 & 40.5 & & \\
\hline No & 86 & 86.5 & 71.9 & & \\
\hline
\end{tabular}

DFS: disease free survival; LRR: local recurrence rate.

presence of LVI was significantly a predicting factor for local recurrence [14]. Willett et al. reported that the depth of perirectal fat invasion by the tumor was an independent factor affecting local recurrence [23]. The study of Tepper et al. showed the number of lymph nodes inspected and the lower rectal cancer were risk factors for local recurrence $[24,25]$. Recently, a prospective study using data from the MRC CR07 and NCICCTG CO16 randomized clinical trial showed that a negative circumferential resection margin and a superior 
Table 3 The multivariable analysis of patients

\begin{tabular}{|c|c|c|c|c|c|c|}
\hline Factors & & $\begin{array}{l}\beta \\
\text { value }\end{array}$ & $\begin{array}{l}\text { SE } \\
\text { value }\end{array}$ & $x^{2}$ & $\begin{array}{l}P \\
\text { value }\end{array}$ & $95 \% \mathrm{Cl}$ \\
\hline & $\begin{array}{l}\text { Pre-operative } \\
\text { CEA }\end{array}$ & & & & & \\
\hline & $\begin{array}{l}\left(<5 \mathrm{ng} / \mathrm{m} \mathrm{L}_{1}\right. \\
\geq 5 \mathrm{ng} / \mathrm{m} \mathrm{L})\end{array}$ & 1.271 & 0.420 & 9.136 & 0.003 & $1.563,8.120$ \\
\hline \multirow[t]{4}{*}{ DFS } & $\begin{array}{l}\text { Number of } \\
\text { lymph nodes }\end{array}$ & & & & & \\
\hline & $(<15, \geq 15)$ & -1.774 & 0.553 & 10.280 & 0.001 & $0.057,0.502$ \\
\hline & $\begin{array}{l}\text { Perirectal fat } \\
\text { infiltration }\end{array}$ & & & & & \\
\hline & (Yes/No) & 0.860 & 0.431 & 3.981 & 0.046 & $1.015,5.501$ \\
\hline \multirow[t]{4}{*}{$\overline{\mathrm{DFS}}$} & $\begin{array}{l}\text { Number of } \\
\text { lymph nodes }\end{array}$ & -1.600 & 0.787 & 4.129 & 0.042 & $0.043,0.945$ \\
\hline & $\begin{array}{l}\text { inspected } \\
(<15, \geq 15)\end{array}$ & & & & & \\
\hline & $\begin{array}{l}\text { Perirectal fat } \\
\text { infiltration }\end{array}$ & 1.617 & 0.700 & 5.338 & 0.021 & $1.278,19.865$ \\
\hline & (Yes/No) & & & & & \\
\hline
\end{tabular}

plane of surgery were associated with low local recurrence rates, while a superior plane of surgery was an independent factor affecting the local recurrence rates [26]. In our study, we found that the pre-operative level of CEA and the number of lymph nodes inspected and perirectal fat infiltration were the independent factors affecting the 5 -year DFS and local recurrence rate. The 5-year DFS was better and the recurrence rate was lower in patients with $\geq 15$ than those with $<15$ lymph nodes. According to a research by Swanson, the 5-year relative survival rate for T3NOM0 colon cancer was $64 \%$ if 1 or 2 lymph nodes were examined and rose to $86 \%$ if 25 lymph nodes were examined, the prognosis of T3N0 colon cancer is dependent on the number of lymph nodes examined [27]. Vather et al. also reported for Stage II and III colonic cancer, lower 5-year mortality was associated with increasing rates of nodal examination [28]. In the previous studies, upper rectal cancers have lower local recurrence rates than mid to lower rectal cancer [29-31]. In our study, we also found that upper rectal cancers have lower recurrence rates than mid to lower rectal cancer, though the difference was not significant $(\mathrm{P}=.115)$. This negative result may due to the small number of patients in our study and increasing the cohort may make it significantly different.

Table 4 The effect of radiotherapy on recurrence in different height of rectal cancer

\begin{tabular}{llllll}
\hline Distance & $\begin{array}{l}\text { Recurrence } \\
\text { rate (\%) }\end{array}$ & P value & CT & CRT & P value \\
\hline $0-5 \mathrm{~cm}$ & 9.8 & 0.115 & $2 / 34(5.9 \%)$ & $4 / 27(14.8 \%)$ & 0.392 \\
$6-10 \mathrm{~cm}$ & 8.9 & - & $3 / 44(6.8 \%)$ & $2 / 12(16.7 \%)$ & 0.289 \\
$11-15 \mathrm{~cm}$ & 0 & - & $0 / 21(0 \%)$ & $0 / 3(0 \%)$ & - \\
\hline
\end{tabular}

Table 5 The effect of radiotherapy on recurrence in different number of lymph nodes

\begin{tabular}{llllll}
\hline Number & $\begin{array}{l}\text { Recurrence } \\
\text { rate (\%) }\end{array}$ & P value & CT & CRT & P value \\
\hline$<15$ & 13.6 & 0.115 & $4 / 37(10.8 \%)$ & $5 / 29(17.2 \%)$ & 0.693 \\
$\geq 15$ & 2.7 & - & $1 / 62(1.6 \%)$ & $1 / 13(7.7 \%)$ & 0.319 \\
\hline
\end{tabular}

This study has several limitations as follows. Firstly, the 5-year OS and LRFS of CRT group were lower than those of CT group. This may partially caused by our selection bias, the patients got adjuvant radiotherapy have more adverse factors such as lower tumor location $(\mathrm{P}=.003)$ and less number of lymph nodes inspected $(P=.001)$. Secondly, our study is a retrospective and nonrandomized analysis with a small sample size, this may not be convincing enough to prove the negative role of additional radiation after TME surgery for patients with no risk factors. Similarly, the little number of sample limits us to demonstrate the positive role for the pT3N0 patients with risk factors. However,we came to a result that was similar to the previous studies which sample sizes were larger than us. Thirdly, all of patients in our study were with negative circumferential resection margins which limit us to clarify the prognostic of patients with positive CRM. Lastly, with respect to location, the local recurrence rate was not of significant difference. A study with large sample will be needed to investigate all of these problems.

\section{Conclusion}

Despite of limitations, we showed the additional radiotherapy did not significantly improve the overall survival and local recurrence rate in patients with pT3NO rectal cancer. The recurrence rate is quite low for patients in CT group. If an optimal TME surgery operated by experienced surgeons guarantee a low local recurrence rate, the risk of post-operative recurrence can be improved through postoperative $\mathrm{CT}$ for rectal cancer patients with few risk factors. For these subgroup patients, adjuvant pelvic radiation after TME needs to be further evaluation. A prospective study is needed to confirm this conclusion.

\section{Competing interests}

The authors declare that they have no competing interests.

\section{Authors' contributions}

JXW designed the study, and YW performed statistical analyses and wrote the manuscript. JXW conceived of the study. NC, LCC, PGB participated in the clinical coordination and revised the manuscript. All authors read and approved the final manuscript.

\section{Acknowledgements}

The study was supported by the Key Clinical Specialty Discipline Construction Program of Fujian Province, and the China National Key Clinical Specialty Discipline Construction Program. 
Received: 14 August 2013 Accepted: 11 July 2014

Published: 22 July 2014

\section{References}

1. Glynne-Jones R, Mathur P, Elton C, Train ML: The multidisciplinary management of gastrointestinal cancer. Multimodal treatment of rectal cancer. Best Pract Res Clin Gastroenterol 2007, 21:1049-1070.

2. The Gastrointestinal Tumor Study Group: Radiation therapy and fluorouracil with or without semustine for the treatment of patients with surgical adjuvant adenocarcinoma of the rectum. J Clin Oncol 1992, 10:549-557.

3. Douglass HO Jr, Moertel CG, Mayer RJ, Thomas PR, Lindblad AS, Mittleman A, Stablein DM, Bruckner HW: Survival after postoperative combination treatment of rectal cancer. N Engl J Med 1986, 315:1294-1295.

4. Consensus NIH: Conference. Adjuvant therapy for patients with colon and rectal cancer. JAMA 1990, 264:1444-1450.

5. Bokey EL, Ojerskog B, Chapuis PH, Dent OF, Newland RC, Sinclair G: Local recurrence after curative excision of the rectum for cancer without adjuvant therapy: role of total anatomical dissection. Br J Surg 1999, 86:1164-1170

6. Nissan A, Stojadinovic A, Shia J, Hoos A, Guillem JG, Klimstra D, Cohen AM, Minsky BD, Paty PB, Wong WD: Predictors of recurrence in patients with $\mathrm{T} 2$ and early $\mathrm{T} 3, \mathrm{~N} 0$ adenocarcinoma of the rectum treated by surgery alone. J Clin Oncol 2006, 24:4078-4084.

7. Enker WE, Thaler HT, Cranor ML, Polyak T: Total mesorectal excision in the operative treatment of carcinoma of the rectum. J Am Coll Surg 1995, 181:335-346.

8. Park IJ, Kim HC, Yu CS, Kim TW, Jang SJ, Kim JC: Effect of adjuvant radiotherapy on local recurrence in stage II rectal cancer. Ann Surg Oncol 2008, 15:519-525.

9. Kim JS, Kim NK, Min BS, Hur H, Ahn JB, Keum KC: Adjuvant radiotherapy following total mesorectal excision for stage IIA rectal cancer: Is it beneficial? Int J Colorectal Dis 2010, 25:1103-1110.

10. Wo JY, Mamon HJ, Ryan DP, Hong TS: T3NO Rectal Cancer: Radiation for All? Semin Radiat Oncol 2011, 21:212-219.

11. Zoccali M, Fichera A: Role of Radiation in Intermediate-Risk Rectal Cancer. Ann Surg Oncol 2012, 19:126-130

12. Sebag-Montefiore D, Stephens RJ, Steele R, Monson J, Grieve R, Khanna S, Quirke P, Couture J, de Metz C, Myint AS, Bessell E, Griffiths G, Thompson LC: Parmar M: Preoperative radiotherapy versus selective postoperative chemoradiotherapy in patients with rectal cancer (MRC CR07 and NCIC-CTG C016): a multicentre, randomised trial. Lancet 2009, 373:811-820.

13. Peeters KC, Marijnen CA, Nagtegaal ID, Kranenbarg EK, Putter H, Wiggers $T_{\text {, }}$ Rutten H, Pahlman L, Glimelius B, Leer JW, van de Velde CJ: The TME trial after a median follow-up of 6years: increased local control but no survival benefit in irradiated patients with resectable rectal carcinoma. Ann Surg 2007, 246:693-701.

14. Kapiteijn E, Marijnen CA, Nagtegaal ID, Putter H, Steup WH, Wiggers T, Rutten HJ, Pahlman L, Glimelius B, van Krieken JH, Leer JW, van de Velde CJ: Preoperative radiotherapy combined with total mesorectal excision for resectable rectal cancer. N Engl J Med 2001, 345:638-646.

15. Merchant NB, Guillem JG, Paty PB, Enker WE, Minsky BD, Quan SH, Wong D, Cohen AM: T3NO rectal cancer: results following sharp mesorectal excision and no adjuvant therapy. J Gastrointest Surg 1999, 3:642-647.

16. Gunderson LL, Sargent DJ, Tepper JE, Wolmark N, O'Connell MJ, Begovic M, Allmer C, Colangelo L, Smalley SR, Haller DG, Martenson JA, Mayer RJ, Rich TA, Ajani JA, MacDonald JS, Willett CG, Goldberg RM: Impact of T and N stage and treatment on survival and relapse in adjuvant rectal cancer: a pooled analysis. J Clin Oncol 2004, 22:1785-1796.

17. Ooi BS, Tjandra JJ, Green MD: Morbidities of adjuvant chemotherapy and radiotherapy for resectable rectal cancer: an overview. Dis Colon Rectum 1999, 42:403-418.

18. Glimelius B, Grönberg H, Järhult J, Wallgren A, Cavallin-Ståhl E: A systematic overview of radiation therapy effects in rectal cancer. Acta Oncol 2003, 42:476-492.

19. Minsky BD, Conti JA, Huang Y, Knopf K: Relationship of acute gastrointestinal toxicity and the volume of irradiated small bowel in patients receiving combined modality therapy for rectal cancer. J Clin Oncol 1995, 13:1409-1416.
20. Paty PB, Enker WE, Cohen AM, Minsky BD, Friedlander-Klar H: Long-term functional results of coloanal anastomosis for rectal cancer. Am J Surg 1994, 167:90-94

21. Shibata D, Guillem JG, Lanouette N, Paty P, Minsky B, Harrison L, Wong WD, Cohen A: Functional and quality-of-life outcomes in patients with rectal cancer after combined modality therapy, intraoperative radiation therapy, and sphincter preservation. Dis Colon Rectum 2000, 43:752-758.

22. Picon Al, Moore HG, Sternberg SS, Minsky BD, Paty PB, Blumberg D, Quan SH, Wong WD, Cohen AM, Guillem JG: Prognostic significance of depth of gross or microscopic perirectal fat invasion in T3NOMO rectal cancers following sharp mesorectal excision and no adjuvant therapy. Int J Colorectal Dis 2003, 18:487-492.

23. Willett CG, Badizadegan K, Ancukiewicz M, Shellito PC: Prognostic factors in stage T3NO rectal cancer: Do all patients require postoperative pelvic irradiation and chemotherapy? Dis Colon Rectum 1999, 42:167-173.

24. Tepper JE, O'Connell M, Niedzwiecki D, Hollis DR, Benson AB 3rd, Cummings B, Gunderson LL, Macdonald JS, Martenson JA, Mayer RJ: Adjuvant therapy in rectal cancer: analysis of stage, sex, and local control-final report of intergroup 0114. J Clin Oncol 2002, 20:1744-1750.

25. Lopez-Kostner F, Lavery IC, Hool GR, Rybicki LA: Fazio VW: Total mesorectal excision is not necessary for cancers of the upper rectum. Surgery 1998, 124:612-617. discussion 617-8.

26. Quirke P, Steele R, Monson J, Grieve R, Khanna S, Couture J, O'Callaghan C, Myint AS, Bessell E, Thompson LC, Parmar M, Stephens RJ, Sebag-Montefiore D: Effect of the plane of surgery achieved on local recurrence in patients with operable rectal cancer: a prospective study using data from the MRC CR07 and NCIC-CTG CO16 randomised clinical trial. Lancet 2009, 373:821-828.

27. Swanson RS, Compton CC, Stewart AK, Bland KI: The prognosis of T3NO colon cancer Is dependent on the number of lymph nodes examined. Ann Surg Oncol 2003, 10:65-71.

28. Vather R, Sammour T, Kahokehr A, Connolly AB, Hill AG: Lymph Node Evaluation and Long-Term Survival in Stage II and Stage III Colon Cancer: A National Study. Ann Surg Oncol 2009, 16:585-593.

29. Folkesson J, Birgisson H, Pahlman L, Cedermark B, Glimelius B, Gunnarsson U: Swedish Rectal Cancer Trial: Long lasting benefits from radiotherapy on survival and local recurrence rate. J Clin Oncol 2005, 23:5644-5650.

30. Faerden AE, Naimy N, Wiik P, Reiertsen O, Weyessa S, Trønnes S, Andersen SN, Bakka A: Total mesorectal excision for rectal cancer. difference in outcome for low and high rectal cancer. Dis Colon Rectum 2005, 48:2224-2231.

31. Lee SH, de Hernandez Anda E, Finne CO, Madoff RD, Garcia-Aguilar J: The effect of circumferential tumor location in clinical outcomes of rectal cancer patients treated with total mesorectal excision. Dis Colon Rectum 2005, 48:2249-2257.

doi:10.1186/1748-717X-9-159

Cite this article as: Wu et al: In the era of total mesorectal excision: adjuvant radiotherapy may be unnecessary for pT3NO rectal cancer. Radiation Oncology 2014 9:159.

\section{Submit your next manuscript to BioMed Central and take full advantage of:}

- Convenient online submission

- Thorough peer review

- No space constraints or color figure charges

- Immediate publication on acceptance

- Inclusion in PubMed, CAS, Scopus and Google Scholar

- Research which is freely available for redistribution 